\title{
Molecular Interaction Study of Binary Mixtures of THF with Methanol and o-Cresol - an Optical and Ultrasonic Study
}

\author{
S. Parveen*, S. Singh, D. Shukla, K.P. Singh, M. Gupta and J.P. Shukla \\ Department of Physics, University of Lucknow, Lucknow-226007, India
}

(Received July 10, 2009; in final form November 10, 2009)

\begin{abstract}
The refractive indices, densities and ultrasonic velocities of binary liquid mixtures of tetrahydrofuran (THF) with methanol and o-cresol over the entire composition range have been measured at 293, 303 and $313 \mathrm{~K}$. Refractive index, density and ultrasonic velocity data have been used to evaluate the molar refraction deviation $\Delta R_{\mathrm{m}}$, deviation in ultrasonic velocity $\Delta u$, excess internal pressure $\pi_{\mathrm{i}}^{\mathrm{E}}$, excess molar enthalpy $H_{\mathrm{m}}^{\mathrm{E}}$ and excess free volume $V_{\mathrm{f}}^{\mathrm{E}}$. The computed results of $\Delta R_{\mathrm{m}}, \Delta u, \pi_{\mathrm{i}}^{\mathrm{E}}, H_{\mathrm{m}}^{\mathrm{E}}$ and $V_{\mathrm{f}}^{\mathrm{E}}$ were fitted to the Redlich-Kister polynomial equation. These results suggest that specific strong interactions are taking place in THF + o-cresol mixture while dispersive forces seem to be responsible for behaviour of THF + methanol mixture. Further, experimental refractive index and density data of these mixtures were also used to test the validity of the empirical/semi-empirical relations and models for refractive index and density, respectively.
\end{abstract}

PACS numbers: 43.35. $+\mathrm{d}, 62.60 .+\mathrm{v}, 82.60 . \mathrm{Lf}$

\section{Introduction}

Complex formation in liquid mixtures has been extensively studied using optical and ultrasonic technique by many workers [1-3]. The formation of hydrogen bond in solutions and its effect on the physical properties of the mixtures have received much attention. Hydrogen bonding plays an important role in fundamental sciences and in industrial applications. Although many experimental and theoretical studies have been directed towards understanding of hydrogen bonding, it remains an area of active research. Knowledge of physico-chemical properties of liquid mixtures formed by two or more components associated through hydrogen bonds is important from theoretical and process design aspects.

Properties such as refractive index, densities and ultrasonic velocities and their variation with temperature and composition of the binary mixture are useful to design engineering processes and in chemical and biological industries. The investigation on the possible changes in these properties of mixtures has been found to be an excellent qualitative and quantitative way to elicit the information about molecular structure and intermolecular forces present in the liquid mixtures.

Tetrahydrofuran (THF) is an excellent aprotic solvent, soluble in all proportions with water, alcohols, ethers, phenols, and all common solvents. It dissolves practically all plastics except certain polyamide and may be

\footnotetext{
* corresponding author; e-mail: shahla47@rediffmail.com
}

useful in polymerization and other chemical reactions, in the cleaning of polymer surfaces, electronic materials etc. [4]. Alcohols/phenols are widely used in the chemical, pharmaceutical, and household industries. Methanol is used as a solvent for fats, oils, paints, varnishes etc. It is also used as antifreeze in automobile radiators and for the manufacture of methyl chloride, methyl esters, and plastics. Phenols are widely used for making explosives, manufacture of bakelite and other dyes.

In order to examine molecular interaction in the mixture of THF with alcohols and phenols through excess optical and acoustical properties, we report here the refractive index $(n)$, density $(\rho)$ and ultrasonic velocity $(u)$ of binary mixtures of THF with methanol and 2-hydroxy-1-methylbenzene 2-methylphenol ortho-hydroxytoluene (o-cresol) over the entire range of composition at $T=$ 293, 303 and $313 \mathrm{~K}$. The experimental values of $n, \rho$ and $u$ were used to calculate the molar refraction deviation $\left(\Delta R_{\mathrm{m}}\right)$, deviation in ultrasonic velocity $(\Delta u)$, excess internal pressure $\left(\pi_{\mathrm{i}}^{\mathrm{E}}\right)$, excess molar enthalpy $\left(H_{\mathrm{m}}^{\mathrm{E}}\right)$ and excess free volume $\left(V_{\mathrm{f}}^{\mathrm{E}}\right)$. These results have been used to discuss the nature of interaction between unlike molecules in terms of hydrogen bonding, dipoledipole interaction and dispersive forces. Further, six mixing rules for prediction of refractive index e.g. LorentzLorenz (L-L), Eykmen (Eyk), Weiner (W), Heller (H), Gladstone-Dale (G-D) and Newton (N) and two models, viz. Hankinson-Brobst-Thomson (HBT) and Rackett for evaluation of density have also been applied to these binary mixtures. A comparative study has been made between experimental and theoretically calculated 
values of refractive indices and densities. The results have been discussed in terms of average percentage deviation (APD). A fairly good agreement has been found between experimental and theoretical values.

\section{Experimental details}

Refractive index was measured using Abbe's refractometer provided by Optics Technologies, Delhi. Refractometer was calibrated by measuring the refractive indices of triply distilled water and benzene at $T=293 \mathrm{~K}$. The accuracy in the refractive index measurement was \pm 0.001 unit. The sample mixtures were directly injected into the prism assembly of the instrument by means of an air tight hypodermic syringe. An average of four to five measurements was taken for a sample mixture.

The density of each liquid mixture has been measured using a pyknometer. The pyknometer consists of a long tube graduated in $0.01 \mathrm{ml}$ scale, fitted to a specific gravity bottle of capacity $8 \mathrm{ml}$. A certain mass of the solution is allowed to expand at the desired temperature and the densities were calculated from the fixed mass and the volume at various temperature. An average of four to five measurements was taken for each sample mixtures.

Ultrasonic velocity was measured using the ultrasonic interferometer (Model M-83) provided by Mittal Enterprises, New Delhi. The instrument was calibrated by measuring the velocity in standard liquids e.g. AR grade benzene and carbon tetrachloride. Our measured values of $u$ at 293, 303 and $313 \mathrm{~K}$ for benzene and carbon tetrachloride agree closely with the values given in literature [5].

Viscosity was measured using LVDV II+Pro viscometer supplied by Brookfield Engineering Laboratories Inc, USA. The viscometer was calibrated with standards whose viscosities are reported in the literature. Each observation was repeated four to five times at each temperature for all compositions. The repeatability of viscosity values is within $\pm 0.2 \%$. The accuracy in the measurement of viscosity is $1 \times 10^{-5} \mathrm{~Pa} \mathrm{~s}$. The temperature was maintained using programmable Brookfield temperature controller model TC-502 with an accuracy of $\pm 0.01^{\circ} \mathrm{C}$.

Mixtures were prepared by weighing the liquids in specially designed ground glass stoppered weighing bottles, taking extreme precautions to minimize preferential evaporation. A Sartorius (BP 121S) single pan balance having a stated precision of $0.1 \mathrm{mg}$ was used throughout. The maximum possible error in the mole fraction is estimated to be \pm 0.0001 . The chemicals used were obtained from Ranbaxy Fine Chemicals Limited. All the chemicals used were purified by standard procedure discussed by Perrin and Armarego [5]. The purities of all chemicals were ascertained by the constancy of their boiling points during final distillation and also by literature comparison [6] of their densities and refractive indices at $293 \mathrm{~K}$. These values agreed well within the precision of experiment error.

\section{Theory}

From the experimental data of refractive index, density and ultrasonic velocity, various thermodynamic parameters such as molar refraction deviation $\left(\Delta R_{\mathrm{m}}\right)$, deviation in ultrasonic velocity $(\Delta u)$, excess internal pressure $\left(\pi_{\mathrm{i}}^{\mathrm{E}}\right)$, excess molar enthalpy $\left(H_{\mathrm{m}}^{\mathrm{E}}\right)$, and excess free volume $\left(V_{\mathrm{f}}^{\mathrm{E}}\right)$ have been evaluated by standard equations:

Deviation in molar refraction

$$
\Delta R_{\mathrm{m}}=\left(\frac{n^{2}-1}{n^{2}+2}\right) V_{\mathrm{m}}-\sum_{i=1}^{2}\left[\left(\frac{n_{i}^{2}-1}{n_{i}^{2}+2}\right) V_{i} \phi_{i}\right] .
$$

Deviation in ultrasonic velocity

$$
\Delta u=u-\sum_{i=1}^{2} x_{i} u_{i}
$$

Excess internal pressure

$$
\pi_{\mathrm{i}}^{\mathrm{E}}=b R T(k)^{1 / 2}\left[\frac{\eta^{1 / 2} \rho^{2 / 3}}{u^{1 / 2} M^{7 / 6}}-\left(\frac{x_{i} \eta_{i}^{1 / 2} \rho_{i}^{2 / 3}}{u_{i}^{1 / 2} M_{i}^{7 / 6}}\right)\right] .
$$

Excess molar enthalpy

$$
H^{\mathrm{E}}=x_{i} \pi_{i 1} V_{1}+x_{2} \pi_{i 2} V_{2}-\pi_{i \mathrm{~m}} V .
$$

Excess free volume

$$
V_{\mathrm{f}}^{\mathrm{E}}=\left(\frac{M_{\mathrm{eff}} u}{\eta k}\right)^{3 / 2}-\left[x_{i}\left(\frac{M_{\mathrm{eff}} u_{i}}{\eta_{i} k}\right)^{3 / 2}\right] .
$$

In Eqs. (1) to (5) $u, \rho, n, \eta$ and $V_{\mathrm{m}}$ stand for ultrasonic velocity, density, refractive index, viscosity and molar volume of the binary mixtures, respectively. $x_{i}, u_{i}$, $\eta_{i}$ and $V_{i}(i=1,2)$ denote respectively the mole fraction, ultrasonic velocity, viscosity, and molar volume of the $i$-th component.

The excess functions were further fitted to RedlichKister polynomial equation

$$
X^{\mathrm{E}}=x(1-x) \sum_{i=1}^{5} A_{i}(1-2 x)^{i},
$$

where $X^{\mathrm{E}}$ is the molar refraction deviation $\left(\Delta R_{\mathrm{m}}\right)$, deviation in ultrasonic velocity $(\Delta u)$, excess internal pressure $\left(\pi_{\mathrm{i}}^{\mathrm{E}}\right)$, excess molar enthalpy $\left(H_{\mathrm{m}}^{\mathrm{E}}\right)$, or excess free volume $\left(V_{\mathrm{f}}^{\mathrm{E}}\right)$ and $x$ is the mole fraction of THF.

The values of Redlich-Kister polynomial coefficient $A_{i}$ were evaluated by the method of least squares and standard deviation $\sigma\left(X^{\mathrm{E}}\right)$ is obtained by

$$
\sigma\left(X^{\mathrm{E}}\right)=\left[\frac{\sum\left(X_{\exp t}-X_{\text {cal }}\right)^{2}}{n-p}\right]^{1 / 2},
$$

where $n$ and $p$ are the number of data points and parameters, respectively.

Also, various empirical/semi-empirical relation and models for the prediction of refractive index and density of liquid mixtures were used as described earlier [7-9].

\section{Results and discussion}

The experimental values of refractive index $(n)$, density $(\rho)$ and ultrasonic velocity $(u)$ for both the mixtures over the entire range of composition are given in Table I 
at temperatures $T=293,303$ and $313 \mathrm{~K}$. The values of the Redlich-Kister polynomial coefficient $A_{i}$ evaluated by the method of least squares along with standard deviation is given in Table II. The values of APD for refractive index and root mean square deviation for density are given in Tables III and IV. Plots of $\Delta R_{\mathrm{m}}, \Delta u, \pi_{\mathrm{i}}^{\mathrm{E}}$, $H_{\mathrm{m}}^{\mathrm{E}}$ and $V_{\mathrm{f}}^{\mathrm{E}}$ against mole fraction of THF for both the mixtures are given in Figs. 1 to 5, respectively.
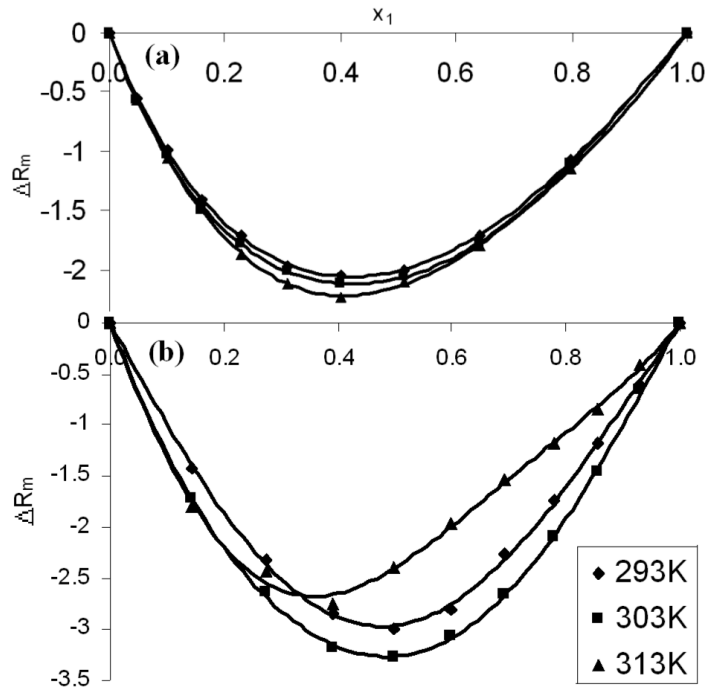

Fig. 1. (a) Molar refraction deviation $\left(\Delta R_{\mathrm{m}}\right)$ as a function of mole fraction of THF $\left(x_{1}\right)$ for THF + methanol mixture. (b) The same as in (a) but for THF + o-cresol mixture.
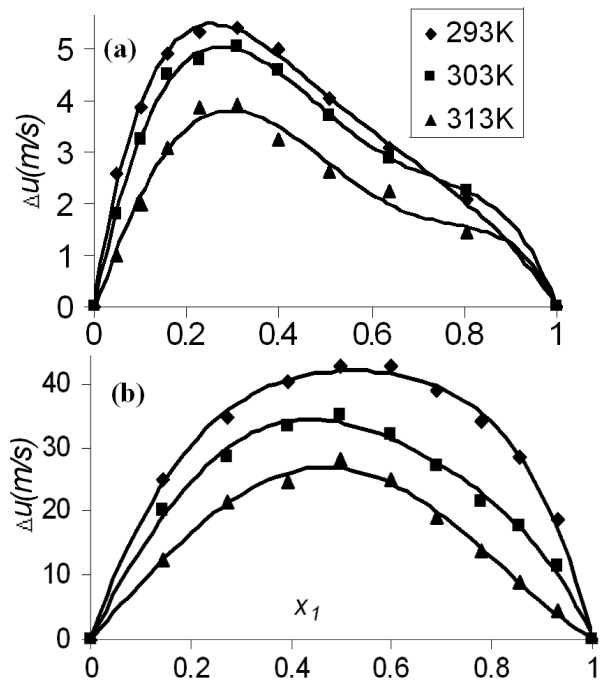

Fig. 2. (a) Deviation in ultrasonic velocity $(\Delta u)$ as a function of mole fraction of THF $\left(x_{1}\right)$ for THF + methanol mixture. (b) The same as in (a), but for $\mathrm{THF}+$ o-cresol mixture.

The values of $\Delta R_{\mathrm{m}}, \Delta u, \pi_{\mathrm{i}}^{\mathrm{E}}, H_{\mathrm{m}}^{\mathrm{E}}$ and $V_{\mathrm{f}}^{\mathrm{E}}$ for the binary mixtures of THF with methanol and o-cresol may be ex-

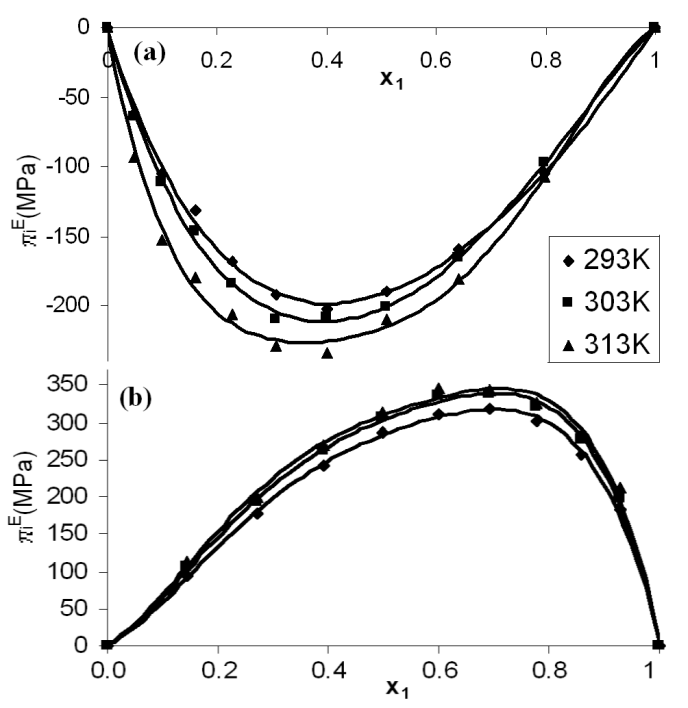

Fig. 3. (a) Excess internal pressure $\left(\pi_{\mathrm{i}}^{\mathrm{E}}\right)$ as a function of mole fraction of THF $\left(x_{1}\right)$ for THF + methanol mixture. (b) The same as in (a), but for THF + o-cresol mixture.

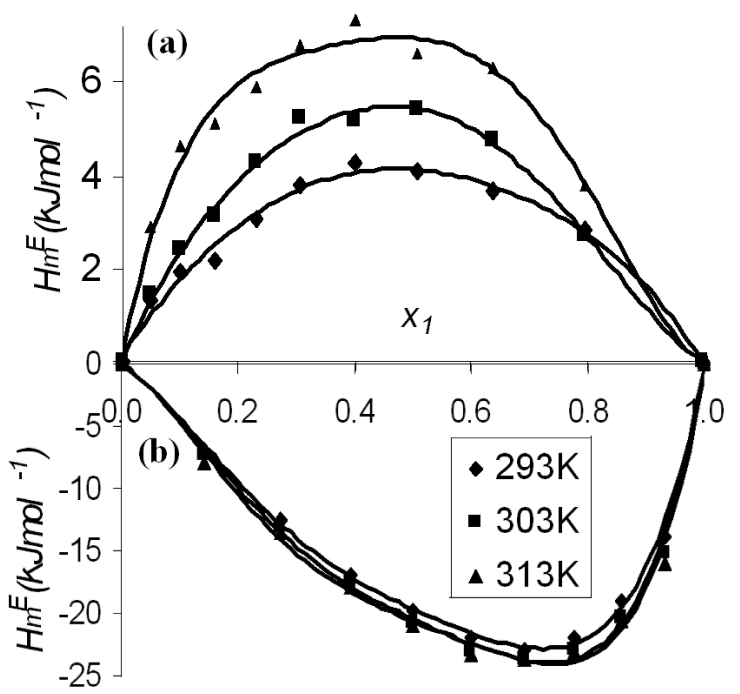

Fig. 4. (a) Excess molar enthalpy $\left(H_{\mathrm{m}}^{\mathrm{E}}\right)$ as a function of mole fraction of THF $\left(x_{1}\right)$ for THF + methanol mixture. (b) The same as in (a), but for THF + o-cresol mixture.

plained as a result of cumulative manifestation of various types of intermolecular interactions between components. It has been reported earlier [10] that the excess thermodynamic properties of the mixtures are influenced by three main types of contribution, viz. (i) physical: due to non-specific Van der Waals type forces; (ii) chemical: due to hydrogen bonding, dipole-dipole, and donor-acceptor interaction between unlike molecules; (iii) structural: due to the fitting of smaller molecules into the voids created by the bigger molecules. The first effect leads to contraction in volume, hence leads to positive contribution 


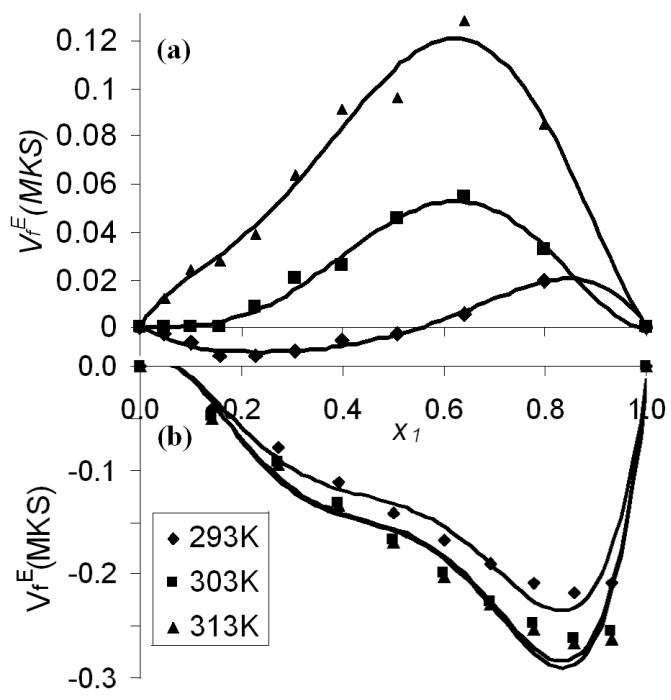

Fig. 5. (a) Excess free volume $\left(V_{\mathrm{f}}^{\mathrm{E}}\right)$ as a function of mole fraction of THF $\left(x_{1}\right)$ for THF + methanol mixture.

(b) The same as in (a), but for THF + o-cresol mixture.

towards $\Delta R_{\mathrm{m}}, H_{\mathrm{m}}^{\mathrm{E}}$ and $V_{\mathrm{f}}^{\mathrm{E}}$ and negative contribution towards $\Delta u$ and $\pi_{\mathrm{i}}^{\mathrm{E}}$. However, the remaining two effects lead to the contraction in volume, resulting in negative $\Delta R_{\mathrm{m}}, H^{\mathrm{E}}$ and $V_{\mathrm{f}}^{\mathrm{E}}$ values and positive $\Delta u$ and $\pi_{\mathrm{i}}^{\mathrm{E}}$ values.

It can be seen from Fig. 1 that $\Delta R_{\mathrm{m}}$ values are negative for both the mixtures at all the temperatures studied here. $\Delta R_{\mathrm{m}}$ gives the strength of interaction in a mixture and is a sensitive function of wavelength, temperature, and mixture composition. $\Delta R_{\mathrm{m}}$ represents the electronic perturbation due to orbital mixing of two components. In the present investigation the order of negative magnitude of $\Delta R_{\mathrm{m}}$ values is (THF + o-cresol) $>$ (THF + methanol). The higher negative values of $\Delta R_{\mathrm{m}}$ for $\mathrm{THF}+\mathrm{o}$-cresol mixture suggest that interaction between THF and o-cresol is stronger as compared to that of between THF and methanol. The effect of temperature on $\Delta R_{\mathrm{m}}$ values is not very significant in the case of $\mathrm{THF}+$ methanol mixture. In the case of THF + o-cresol mixture, no significant change in $\Delta R_{\mathrm{m}}$ values with temperature has been found if temperature is raised from 293 to $303 \mathrm{~K}$ however, an appreciable change is observed in $\Delta R_{\mathrm{m}}$ values at $313 \mathrm{~K}$ in $\mathrm{THF}$ rich region.

The plots of deviation in ultrasonic velocity $\Delta u$ with mole fraction at all the three temperatures for both the mixtures exhibit positive values. The positive values of $\Delta u$ decrease with increase in temperature which indicates the decrease in strength of interaction with temperature in both the mixtures. The higher positive value of $\Delta u$ in the case of THF + o-cresol mixture than that of $\mathrm{THF}+$ methanol mixture may be due to the fact that the $-\mathrm{OH}$ group attached to an aromatic ring is more acidic than - $\mathrm{OH}$ group attached to an alkyl group, thus exhibiting higher positive values in the case of THF + o-cresol mixture.
It is well known that THF is an aprotic liquid and when mixed with methanol/o-cresol (protic liquids), it tends to break the associates present in the methanol/o-cresol molecules. The higher negative values of $\Delta R_{\mathrm{m}}$ and positive values of $\Delta u$ in THF + o-cresol indicate the presence of strong intermolecular interaction through hydrogen bonding between oxygen atom of THF with the hydrogen atom of hydroxyl group of o-cresol. It is due to the fact that $-\mathrm{OH}$ group attached to the benzene ring in case of o-cresol is stabilized to a greater extent through resonance as compared to alcoholic - $\mathrm{OH}$ group of methanol. Similar results of $\Delta R_{\mathrm{m}}$ and $\Delta u$ have been reported earlier [10-12].

The $\pi_{i}^{\mathrm{E}}$ values are found to be negative over the entire mole fraction of the THF in the binary mixture of THF + methanol (Fig. 3). The negative contribution of $\pi_{\mathrm{i}}^{\mathrm{E}}$ values is an evidence of the presence of weak molecular interaction between the components present in the mixtures. For the mixture of THF + o-cresol, $\pi_{\mathrm{i}}^{\mathrm{E}}$ values are found to be positive, which indicates the presence of strong hydrogen bonding due to the charge transfer complex. Similar results were observed in the mixtures of TEA alcohols [13]. No significant change in $\pi_{i}^{\mathrm{E}}$ values with temperature has been observed in THF + o-cresol mixture. The negative values of $\pi_{\mathrm{i}}^{\mathrm{E}}$ in the case of THF + methanol increase with increase in temperature, suggesting an increase in self-association of the pure component and decrease in strength of interaction with temperature.

The values of excess molar enthalpy $H_{\mathrm{m}}^{\mathrm{E}}$ can be interpreted in terms of the formation of intermolecular hydrogen bonding and the breaking of associated structures of the THF with methanol/o-cresol. The $H_{\mathrm{m}}^{\mathrm{E}}$ values are negative for THF + o-cresol but positive in case of $\mathrm{THF}+$ methanol. The negative values of $H_{\mathrm{m}}^{\mathrm{E}}$ in the mixture of $\mathrm{THF}+\mathrm{o}$-cresol indicate the presence of strong interaction between unlike molecules. However, the interaction between THF and methanol may lead to weak dispersion type forces due to rupture of hydrogen bonded self-association in methanol molecules giving rise to positive values in $H_{\mathrm{m}}^{\mathrm{E}}$. Similar variation in $H_{\mathrm{m}}^{\mathrm{E}}$ with composition has also been reported earlier [14].

Excess free volume $\left(V_{\mathrm{f}}^{\mathrm{E}}\right)$ is found to be negative for the binary mixture of THF with o-cresol over the entire composition range and absolute values of $V_{\mathrm{f}}^{\mathrm{E}}$ increases as the temperature is raised, suggesting an increase in intermolecular interaction between unlike molecules due to thermal energy. For the mixture of THF + methanol the values of $V_{\mathrm{f}}^{\mathrm{E}}$ at $293 \mathrm{~K}$ is found to be small negative in methanol rich region and turns to positive in THF rich region. At the temperatures 303 and $313 \mathrm{~K}$, the values of $V_{\mathrm{f}}^{\mathrm{E}}$ are found to be positive. The negative values of $V_{\mathrm{f}}^{\mathrm{E}}$ suggest the existence of strong dipole-dipole type of interaction through hydrogen bonding between oxygen atom of THF and hydrogen atom of hydroxyl group in $\mathrm{o}$-cresol in case of THF $+\mathrm{o}$-cresol mixture, where as positive values of $V_{\mathrm{f}}^{\mathrm{E}}$ indicate the predominance of dispersive forces in case of $\mathrm{THF}+$ methanol. 
TABLE I

Refractive index $(n)$, density $(\rho)$, ultrasonic velocity $(u)$, for the binary mixtures of THF + methanol and THF + o-cresol at varying temperatures.

\begin{tabular}{|c|c|c|c|c|c|c|c|c|c|}
\hline \multirow[t]{2}{*}{$x_{1}$} & \multicolumn{3}{|c|}{$T=293 \mathrm{~K}$} & \multicolumn{3}{|c|}{$T=303 \mathrm{~K}$} & \multicolumn{3}{|c|}{$T=313 \mathrm{~K}$} \\
\hline & $n$ & $\begin{array}{c}\rho \\
{\left[\mathrm{g} / \mathrm{cm}^{3}\right]}\end{array}$ & $\begin{array}{c}u \\
{[\mathrm{~m} / \mathrm{s}]}\end{array}$ & $n$ & $\begin{array}{c}\rho \\
{\left[\mathrm{g} / \mathrm{cm}^{3}\right]}\end{array}$ & $\begin{array}{c}u \\
{[\mathrm{~m} / \mathrm{s}]}\end{array}$ & $n$ & $\begin{array}{c}\rho \\
{\left[\mathrm{g} / \mathrm{cm}^{3}\right]}\end{array}$ & $\begin{array}{c}u \\
{[\mathrm{~m} / \mathrm{s}]}\end{array}$ \\
\hline \multicolumn{10}{|c|}{ THF + methanol } \\
\hline 0.0000 & 1.330 & 0.7958 & 1116.0 & 1.325 & 0.7951 & 1084.0 & 1.321 & 0.7858 & 1050.0 \\
\hline 0.0470 & 1.336 & 0.8055 & 1127.4 & 1.331 & 0.8045 & 1093.6 & 1.328 & 0.7975 & 1058.3 \\
\hline 0.0999 & 1.345 & 0.8153 & 1138.6 & 1.339 & 0.8134 & 1103.8 & 1.335 & 0.8073 & 1067.6 \\
\hline 0.1598 & 1.352 & 0.8252 & 1150.8 & 1.345 & 0.8227 & 1115.0 & 1.343 & 0.8169 & 1078.0 \\
\hline 0.2284 & 1.361 & 0.8350 & 1164.1 & 1.355 & 0.8317 & 1126.7 & 1.349 & 0.8265 & 1089.5 \\
\hline 0.3075 & 1.368 & 0.8451 & 1178.9 & 1.363 & 0.8409 & 1140.1 & 1.357 & 0.8361 & 1101.9 \\
\hline 0.3998 & 1.377 & 0.8548 & 1195.8 & 1.371 & 0.8495 & 1155.0 & 1.365 & 0.8454 & 1115.6 \\
\hline 0.5090 & 1.384 & 0.8641 & 1215.2 & 1.379 & 0.8582 & 1172.2 & 1.375 & 0.8533 & 1132.0 \\
\hline 0.6399 & 1.393 & 0.8755 & 1238.7 & 1.387 & 0.8678 & 1193.1 & 1.383 & 0.8614 & 1152.0 \\
\hline 0.7994 & 1.401 & 0.8837 & 1267.6 & 1.396 & 0.8748 & 1219.0 & 1.391 & 0.8671 & 1176.1 \\
\hline 1.0000 & 1.410 & 0.8935 & 1303.0 & 1.405 & 0.8828 & 1250.0 & 1.400 & 0.8735 & 1205.9 \\
\hline \multicolumn{10}{|c|}{$\mathrm{THF}+$ o-cresol } \\
\hline 0.0000 & 1.550 & 1.0515 & 1554.5 & 1.546 & 1.0487 & 1525.0 & 1.542 & 1.0391 & 1462.0 \\
\hline 0.1434 & 1.514 & 1.0421 & 1543.6 & 1.509 & 1.0442 & 1505.6 & 1.472 & 1.0390 & 1437.8 \\
\hline 0.2735 & 1.488 & 1.0329 & 1520.3 & 1.484 & 1.0375 & 1478.4 & 1.438 & 1.0385 & 1413.3 \\
\hline 0.3921 & 1.468 & 1.0237 & 1496.1 & 1.465 & 1.0322 & 1450.7 & 1.415 & 1.0307 & 1386.2 \\
\hline 0.4999 & 1.452 & 1.0099 & 1471.6 & 1.450 & 1.0177 & 1422.6 & 1.410 & 1.0205 & 1361.9 \\
\hline 0.5999 & 1.440 & 0.9919 & 1446.2 & 1.438 & 0.9997 & 1392.0 & 1.409 & 1.0054 & 1333.4 \\
\hline 0.6923 & 1.434 & 0.9724 & 1419.3 & 1.429 & 0.9791 & 1361.6 & 1.407 & 0.9829 & 1303.7 \\
\hline 0.7778 & 1.427 & 0.9516 & 1392.8 & 1.422 & 0.9570 & 1332.5 & 1.405 & 0.9586 & 1276.8 \\
\hline 0.8571 & 1.420 & 0.9296 & 1367.4 & 1.415 & 0.9323 & 1307.0 & 1.403 & 0.9325 & 1251.4 \\
\hline 0.9310 & 1.414 & 0.9103 & 1339.1 & 1.409 & 0.9017 & 1280.3 & 1.403 & 0.9039 & 1227.9 \\
\hline 1.0000 & 1.410 & 0.8935 & 1303.0 & 1.405 & 0.8828 & 1250.0 & 1.402 & 0.8735 & 1205.9 \\
\hline
\end{tabular}

TABLE III

APD values of various empirical/semi-empirical relations for refractive index of the binary mixtures at varying temperatures.

\begin{tabular}{|c|c|c|c|c|c|c|c|}
\hline $\begin{array}{c}\text { Temperature } \\
{[\mathrm{K}]}\end{array}$ & $\begin{array}{l}\text { Lorentz } \\
\text {-Lorenz }\end{array}$ & Eykmen & Weiner & Heller & $\begin{array}{c}\text { Gladstone } \\
\text {-Dale }\end{array}$ & $\begin{array}{l}\text { Arago } \\
- \text { Biot }\end{array}$ & Newton \\
\hline \multicolumn{8}{|c|}{ THF + methanol } \\
\hline 293 & -0.0295 & -0.0413 & 0.0140 & 0.0334 & 0.0068 & 0.0068 & -0.0188 \\
\hline 303 & -0.1014 & -0.1120 & -0.0273 & -0.0078 & -0.0346 & -0.0346 & -0.0604 \\
\hline 313 & -0.2017 & -0.2065 & -0.0241 & -0.0050 & -0.0313 & -0.0313 & -0.0566 \\
\hline \multicolumn{8}{|c|}{$\mathrm{THF}+\mathrm{o}$-cresol } \\
\hline 293 & -1.8935 & -1.8963 & -1.3729 & -1.2940 & -1.4016 & -1.4016 & -1.4701 \\
\hline 303 & -2.2192 & -2.1895 & -1.3352 & -1.2571 & -1.3644 & -1.3644 & -1.4343 \\
\hline 313 & -4.0822 & -4.0190 & -1.3612 & -1.4365 & -1.5315 & -1.5315 & -1.5938 \\
\hline
\end{tabular}


TABLE II

The values of coefficient $A_{i}$ from Eq. (4) for $\Delta R_{\mathrm{m}}, \Delta u, \pi_{\mathrm{i}}^{\mathrm{E}}, H_{\mathrm{m}}^{\mathrm{E}}$ and $V_{\mathrm{f}}^{\mathrm{E}}$ and standard deviation $\sigma\left(X^{\mathrm{E}}\right)$ for binary mixtures at varying temperatures.

\begin{tabular}{|c|c|c|c|c|c|c|}
\hline Functions & $A_{1}$ & $\overline{A_{2}}$ & $A_{3}$ & $A_{4}$ & $\overline{A_{5}}$ & $\sigma\left(X^{\mathrm{E}}\right)$ \\
\hline \multicolumn{7}{|c|}{ THF + methanol } \\
\hline \multicolumn{7}{|c|}{$\mathrm{T}=293 \mathrm{~K}$} \\
\hline$\Delta R_{\mathrm{m}}$ & -8.0649 & -2.3178 & -0.1746 & -1.0816 & -1.8347 & 0.0187 \\
\hline$\Delta u[\mathrm{~m} / \mathrm{s}]$ & 21.3428 & 22.8657 & -35.8964 & -26.4177 & 96.8663 & 0.0492 \\
\hline$\pi_{\mathrm{i}}^{\mathrm{E}}[\mathrm{MPa}]$ & -761.2152 & -292.5867 & -113.4095 & -70.2333 & -328.8603 & 2.3494 \\
\hline$H_{\mathrm{m}}^{\mathrm{E}}[\mathrm{kJ} / \mathrm{mol}]$ & 19.4931 & 7.3096 & -28.6004 & -21.5464 & 63.5626 & 0.1067 \\
\hline$V_{\mathrm{f}}^{\mathrm{E}}[\mathrm{mks}]$ & -0.0123 & -0.0933 & 0.0598 & -0.1643 & 0.1749 & 0.0007 \\
\hline \multicolumn{7}{|c|}{$\mathrm{T}=303 \mathrm{~K}$} \\
\hline$\Delta R_{\mathrm{m}}$ & -8.2992 & -1.7808 & 0.4790 & -2.0816 & -2.3823 & 0.0200 \\
\hline$\Delta u[\mathrm{~m} / \mathrm{s}]$ & 15.1434 & 15.7255 & 21.5699 & -5.5098 & -4.2494 & 0.1054 \\
\hline$\pi_{\mathrm{i}}^{\mathrm{E}}[\mathrm{MPa}]$ & -804.1461 & -297.5899 & -60.1121 & -294.5103 & -157.5137 & 2.9542 \\
\hline$H_{\mathrm{m}}^{\mathrm{E}}[\mathrm{kJ} / \mathrm{mol}]$ & 21.8439 & 1.6209 & -1.0600 & 16.5019 & 0.1834 & 0.1439 \\
\hline$V_{\mathrm{f}}^{\mathrm{E}}[\mathrm{mks}]$ & 0.2241 & -0.1687 & -0.4342 & 0.0635 & 0.3744 & 0.0021 \\
\hline \multicolumn{7}{|c|}{$\mathrm{T}=313 \mathrm{~K}$} \\
\hline$\Delta R_{\mathrm{m}}$ & -8.4863 & -2.9155 & -2.5536 & -1.1289 & 2.1304 & 0.0122 \\
\hline$\Delta u[\mathrm{~m} / \mathrm{s}]$ & 10.6435 & 7.2891 & 33.9448 & 14.6663 & -49.1056 & 0.0691 \\
\hline$\pi_{\mathrm{i}}^{\mathrm{E}}[\mathrm{MPa}]$ & -840.1937 & -273.6678 & -544.1868 & -837.8628 & 160.0759 & 2.1949 \\
\hline$H_{\mathrm{m}}^{\mathrm{E}}[\mathrm{kJ} / \mathrm{mol}]$ & 26.7517 & 2.2101 & 33.5119 & 26.2267 & -59.4433 & 0.1135 \\
\hline$V_{\mathrm{f}}^{\mathrm{E}}[\mathrm{MKS}]$ & 0.3775 & -0.2961 & 1.6530 & 0.4315 & -4.1021 & 0.0025 \\
\hline \multicolumn{7}{|c|}{ THF + o-cresol } \\
\hline \multicolumn{7}{|c|}{$\mathrm{T}=293 \mathrm{~K}$} \\
\hline$\Delta R_{\mathrm{m}}$ & -11.4843 & 0.5736 & -4.3434 & -0.9981 & 8.3115 & 0.2399 \\
\hline$\Delta u[\mathrm{~m} / \mathrm{s}]$ & 169.7401 & -12.2758 & 26.9729 & -19.5989 & 144.1307 & 0.1563 \\
\hline$\pi_{\mathrm{i}}^{\mathrm{E}}[\mathrm{MPa}]$ & 1145.2185 & -654.6949 & 434.2726 & -756.6871 & 569.0823 & 0.6962 \\
\hline$H_{\mathrm{m}}^{\mathrm{E}}[\mathrm{kJ} / \mathrm{mol}]$ & -79.5944 & 49.7274 & -48.2669 & 58.2781 & -34.2709 & 0.0512 \\
\hline$V_{\mathrm{f}}^{\mathrm{E}}[\mathrm{mks}]$ & -0.5496 & 0.5001 & -0.8111 & 1.5753 & -1.1589 & 0.0001 \\
\hline \multicolumn{7}{|c|}{$\mathrm{T}=303 \mathrm{~K}$} \\
\hline$\Delta R_{\mathrm{m}}$ & -12.6068 & 0.3203 & -3.9253 & -3.5663 & 6.1984 & 0.0109 \\
\hline$\Delta u[\mathrm{~m} / \mathrm{s}]$ & 73.0446 & 29.6881 & -46.3068 & -16.0555 & 146.5308 & 0.1990 \\
\hline$\pi_{\mathrm{i}}^{\mathrm{E}}[\mathrm{MPa}]$ & 1400.5242 & -598.2963 & -942.8600 & -754.7349 & 2462.7654 & 1.0663 \\
\hline$H_{\mathrm{m}}^{\mathrm{E}}[\mathrm{kJ} / \mathrm{mol}]$ & -80.9750 & 44.3214 & -52.5769 & 80.7032 & -46.5922 & 0.0674 \\
\hline$V_{\mathrm{f}}^{\mathrm{E}}[\mathrm{mks}]$ & -0.6503 & 0.5950 & -1.0085 & 1.9679 & -1.4323 & 0.0002 \\
\hline \multicolumn{7}{|c|}{$\mathrm{T}=313 \mathrm{~K}$} \\
\hline$\Delta R_{\mathrm{m}}$ & -10.4417 & -14.1117 & -10.3441 & 17.0894 & 19.1064 & 0.0274 \\
\hline$\Delta u[\mathrm{~m} / \mathrm{s}]$ & 49.4133 & 22.2534 & -68.5257 & 8.9843 & 48.4489 & 0.7037 \\
\hline$\pi_{\mathrm{i}}^{\mathrm{E}}[\mathrm{MPa}]$ & 1182.9498 & -194.9630 & -115.6796 & -1537.2599 & 1896.7832 & 1.7236 \\
\hline$H_{\mathrm{m}}^{\mathrm{E}}[\mathrm{kJ} / \mathrm{mol}]$ & -126.2184 & 60.1125 & 225.1732 & 25.3596 & -402.1696 & 0.1266 \\
\hline$V_{\mathrm{f}}^{\mathrm{E}}[\mathrm{mks}]$ & -0.6365 & 0.4151 & -0.7447 & 2.2738 & -1.9696 & 0.0001 \\
\hline
\end{tabular}

Further, the refractive index and density of the mixtures were correlated using the empirical/semi-empirical relations and models as reported earlier [7, 8]. The experimental refractive index data of $\mathrm{THF}+$ methanol/o-cresol binary mixtures were compared with the corresponding calculated values using six empirical relations viz. L-L, Eyk, W, H, G-D, and N. It is evident from Tables III and IV that all empirical relations exhibit fairly good result in the case of THF + methanol with maximum APD of - 0.2065 using Eyk relations and min- 
TABLE IV

Root mean square deviation of various models for density of THF + methanol mixture at varying temperatures.

\begin{tabular}{c|c|c}
\hline \hline Temperature [K] & HBT & Rackelt \\
\hline 293 & 0.13617 & 0.66383 \\
303 & 0.06862 & 0.76389 \\
313 & 0.06853 & 0.84663
\end{tabular}

imum APD of -0.0050 using $\mathrm{H}$ relation. However, in the case of THF + o-cresol, APD values are quite higher as compared to $\mathrm{THF}+$ methanol mixture but well within limit with maximum APD of -4.0822 by $\mathrm{L}-\mathrm{L}$ relation and minimum APD of -1.2571 by Heller's relation. The mixing rule proposed by Weiner and Gladstone-Dale are more suitable for prediction of refractive index data in binary mixtures of THF + methanol. The density of $\mathrm{THF}+$ methanol mixture was calculated using HBT and Rackett model. The predicted values of densities at varying temperature are compared with experimentally measured densities. It is evident from Table IV that HBT model is more suitable than the Rackett model for the prediction of density of the binary mixture of THF + methanol. However, in case of $\mathrm{THF}+\mathrm{o}$-cresol mixture, these models could not be applied due to non-availability of data of critical volume.

\section{Conclusions}

(i) The negative values of $\Delta R_{\mathrm{m}}, H_{\mathrm{m}}^{\mathrm{E}}$ and $V_{\mathrm{f}}^{\mathrm{E}}$ and positive values of $\Delta u$ and $\pi_{\mathrm{i}}^{\mathrm{E}}$ for THF + o-cresol mixture are attributed to the strong intermolecular interaction between unlike molecules. However, the positive and negative values of these parameters in case of $\mathrm{THF}+$ methanol indicate the predominance of dispersive forces.

(ii) Comparison of experimental and estimated values of refractive indices and densities in terms of APD and root mean square deviation exhibit the suitability of six empirical relations and two models for representing the mixing refractive indices and densities, respectively.

\section{Acknowledgments}

One of the authors (K.P. Singh) is grateful to UGC New Delhi for financial assistance.

\section{References}

[1] B. Gonzalez, A. Dominguez, Jose Tojo, R. Cores, J. Chem. Eng. Data 49, 1225 (2004).

[2] J. Wu, Z. Xu, Z. Liu, B. Wang, J. Chem. Eng. Data 50, $966(2005)$.

[3] U.B. Kadam, A.P. Hiray, A.B. Sawant, M. Hassan, J. Chem. Eng. Data 51, 60 (2006).

[4] H. Iloukhani, N. Zoorasna, R. Soleimani, J. Phys. Chem. Liquids 43, 391 (2005).

[5] D.D. Perrin, W.L.F. Armarego, Purification of Lab. Chem., 3rd ed., Pergamon Press, Oxford 1980.

[6] CRC Handbook of Chemistry and Physics, Ed. D.R. Lide, 76th ed., CRC Press, 1995-1996, p. 32.

[7] A. Misra, I. Vibhu, R.K. Singh, M. Gupta, J.P. Shukla, J. Phys. Chem. Liquids 45, 93 (2007).

[8] J.M. Resa, C. Gonzalez, S. Prieto, E. Diez, M. Iglesias, Korean J. Chem. Eng. Data 23, 93 (2006).

[9] M. Gupta, D. Shukla, S. Parveen, S. Singh, J.P. Shukla, J. Phys. Chem. Liquids 47, 113 (2009).

[10] S. Parveen, D. Shukla, S. Singh, K.P. Singh, M. Gupta, J.P. Shukla, Appl. Acoust. 70, 507 (2009).

[11] J.N. Nayak, M.I. Aralaguppi, B.V.K. Naidu, T.M. Aminabhavi, J. Chem. Eng. Data 49, 468 (2004).

[12] J.M. Resa, C. Gonzalez, S. Ortiz de Landaluce, Juan Lanz, J. Chem. Thermodynamics 34, 1013 (2002).

[13] V. Rajendran, Ind. J. Pure Appl. Phys. 31, 812 (1993).

[14] B.S. Bjola, M.A. Siddiqi, U. Fornefeld-Schwarz, P. Svejda, J. Chem. Eng. Data 47, 250 (2002). 